\title{
A survey of pediatric postoperative pain management in Rwanda
}

\author{
Brigitte Kalala, MD, Mmed · Daniel Ferguson, BSc $\cdot$ Francoise Nizeyimana, MD, Mmed $\cdot$ \\ Shefali Thakore, MD · Jean Paul Myukiyehe, MD, Mmed - Theogene Twagirumugabi, MD, Mmed, PhD • \\ Gaston Nyirigira, MD, Mmed · Paulin Banguti, MD, Mmed · Jennifer O'Brien, PhD · William McKay, MD (1)
}

Received: 17 May 2021/Revised: 21 June 2021/Accepted: 20 July 2021/Published online: 4 August 2021

(C) Canadian Anesthesiologists' Society 2021

Keywords postoperative $\cdot$ pediatric $\cdot$ pain $\cdot$ Rwanda

\section{To the Editor,}

Research in sub-Saharan Africa has described shortages of pediatric anesthesia airway equipment, medications, training, and personnel. Previous work by our group has shown postoperative pain management of adults in Rwanda, a low income country (LIC), to be inadequate but improving. ${ }^{1,2}$ Here, we report results of an initial study on the impact of these conditions on postoperative pain in children.

With approval of the ethics committees of the Universities of Saskatchewan and Rwanda and of the hospitals, we conducted a prospective observational study from July 2019 to December 2019 of postoperative pain management in children aged 3-16 yr in the teaching hospitals in Kigali and Butare. We obtained consent from parents and assent from children in their preferred language. Participants were invited in the preoperative holding area and followed in the recovery room and ward until postoperative day 2, when the validated Faces Pain

B. Kalala, MD, Mmed · F. Nizeyimana, MD, Mmed

University of Rwanda, Kigali, Rwanda

College of Medicine and Health Sciences, Kigali, Rwanda

D. Ferguson, BSc $\cdot \mathrm{S}$. Thakore, MD $\cdot$ J. O'Brien, $\mathrm{PhD}$.

W. McKay, MD ( $\square)$

University of Saskatchewan, Saskatoon, SK, Canada

e-mail: bill.mckay@usask.ca

J. P. Myukiyehe, MD, Mmed · T. Twagirumugabi, MD, Mmed, $\mathrm{PhD} \cdot$ G. Nyirigira, MD, Mmed · P. Banguti, MD, Mmed

University of Rwanda, Kigali, Rwanda
Scale - Revised ${ }^{3}$ and the International Pain Outcomes Questionnaire (IPOQ) ${ }^{4}$ were administered. The latter scale has not been validated in children, but a parent was always present when it was administered by an interviewer. It has been used in LICs. ${ }^{5}$ There are no similar pediatric studies in LICs from which to calculate a sample size. We planned on approaching 100 participants, but include data obtained when that number was exceeded because of simultaneous research at two hospitals. We assessed all scale data for normality (Shapiro-Wilk test) and none was Gaussian $(P<$ 0.001). We calculated $99 \%$ confidence intervals (CI) for categorical questions.

We approached 105 patients with their parents, and all agreed to participate: 90 in Kigali and 15 in Butare; 28 female, 77 male; median [interquartile range (IQR)] age, 8 [4-12] yr. They had 81 major surgeries requiring hospital admission and 24 minor day surgeries. By specialty, there were eight otolaryngology, 24 general, 49 orthopedic, 14 plastic, six urology, two neurosurgery, and two others (a bone marrow aspiration and a complex case involving multiple specialties). Twelve had pre-existing pain.

The primary outcome, median [IQR] patient's worst pain score in the first $48 \mathrm{hr}$ after surgery, was 6 [4-8]; range, $2-10$. More than half (58/105) had severe pain with a score of 7 or more. Eighty-one were at risk of severe postoperative pain because of pre-existing pain or major surgery. Only 25/105 (24\%) patients were assessed for pain by recovery room staff post-surgery, and of these, only 18 were medicated. All were given pain medication on the surgical or pediatric intensive care ward. Drugs used were combinations of paracetamol, non-steroidal antiinflammatory drugs (NSAIDs), and opioids. Overall, paracetamol was used in 90/105 $(86 \%)$ patients, NSAIDs in $73 / 105(70 \%)$, and opioids in $43 / 105(41 \%)$. Seven 
Table 1 Perioperative patient management details and International Pain Outcomes Questionnaire results

Perioperative management details

Preoperative, $n /$ total $N(\% ; 99 \% \mathrm{CI})$

Discussed postoperative pain

$28 / 105(26 \% ; 16$ to 38$)$

Operating room, $n$ or ${ }^{a} n /$ total $N(\% ; 99 \% \mathrm{CI})$

\begin{tabular}{|c|c|c|}
\hline Surgery duration & Anesthetic & Opioid $^{\mathrm{a}}$ \\
\hline$<1$ hr 12 & GA 99 & $89 / 92$ (97\%; 92 \\
\hline $1-2$ hr 52 & SA 2 & \\
\hline$>2-4 \mathrm{hr} 36$ & $\mathrm{GA}+\mathrm{RA} 1$ & \\
\hline \multirow[t]{2}{*}{$>4 \mathrm{hr} 5$} & $\mathrm{SA}+\mathrm{RA} 1$ & \\
\hline & Sedation 1 & \\
\hline \multicolumn{3}{|c|}{ Postanesthesia care unit, $n /$ total $N(\% ; 99 \% \mathrm{CI})$ or ${ }^{\mathrm{b}} n$} \\
\hline Pain evaluated & Pain medication & Time until \\
\hline $25 / 104$ & $18 / 103$ & administration $^{\mathrm{b}}$ \\
\hline \multirow[t]{3}{*}{$(24 \% ; 13$ to 35$)$} & $(17 \% ; 8$ to 27$)$ & $<15 \min 16$ \\
\hline & & $15-30 \min 1$ \\
\hline & & $31-60 \min 0$ \\
\hline
\end{tabular}

Ward medication, $n$ or ${ }^{\text {a }} n /$ total $N(\%$; $99 \% \mathrm{CI})$

Paracetamol $93 \quad$ As scheduled ${ }^{\mathrm{a}}$

NSAID 71

$65 / 83$

Opioid 45

( $78 \% ; 67$ to 90$)$
If requested by parent ${ }^{\mathrm{a}}$

\section{$22 / 46$}

$(48 \% ; 29$ to 67$)$
LA injected into wound ${ }^{\mathrm{a}}$

$4 / 102$ (4\%; -1 to 9$)$

IPOQ results

Item ( ${ }^{\mathrm{c}}$ scale of $\left.1-10\right),{ }^{\mathrm{d}}$ median [IQR] (range); or ${ }^{\mathrm{a}} n /$ total $N(\% ; 99 \% \mathrm{CI})$

P1 Worst pain first 2 postoperative days ${ }^{\mathrm{c}, \mathrm{d}}$

P2 Least pain first 2 postoperative days ${ }^{\mathrm{c}, \mathrm{d}}$

P3 Percent of time pain is severe ${ }^{\mathrm{d}}$

7 [5-8] $(2-10)$

P4 Pain interference with activities

P4a Moving ${ }^{\mathrm{c}, \mathrm{d}}$

P4b Breathing ${ }^{c, d}$

P4c Sleeping ${ }^{c, d}$

P4d Prevented getting out of bed ${ }^{\mathrm{a}}$

P5a Scared by pain ${ }^{\text {c,d }}$

P6 Adverse effects ${ }^{\mathrm{c}, \mathrm{d}}$

P6a Nausea

2 [1-2] $(0-8)$

$50 \%$ [30-70] (0-90)

P6b Drowsiness

4 [2-6] (0-10)

0 [0-2] (0-9)

$0[0-4](0-7)$

$5 / 105(5 \% ; 1$ to 10$)$

$2[0-4](0-10)$

P6c Itch

$0[0-0](0-10)$

0 [0-0] (0-8)

0 [0-0] (0-9)

0 [0-0] (0-6)

P6d Dizziness

P7 Percent pain relief since surgery ${ }^{\mathrm{d}}$

P8 Patients who wanted more pain relief ${ }^{a}$

$70 \%$ [60-80] (10-100)

$21 / 105(20 \% ; 10$ to 30$)$

P9 Patients informed about pain management $\mathrm{t}^{\mathrm{a}}$

P10 Patients' participation in pain decisions satisfaction ${ }^{\mathrm{c}, \mathrm{d}}$

9/104 $(10 \% ; 2$ to 16$)$

P11 Overall satisfaction ${ }^{\mathrm{c}, \mathrm{d}}$

6 [2-8] (0-10)

P12 Patients receiving non-drug pain relievers ${ }^{\mathrm{a}, *}$

8 [7-9] (2-10)

P12a Ice pack

$2 / 105$ ( $2 \% ;-2$ to 5$)$

P12b Prayer

$58 / 105$ (55\%; 43 to 68$)$

P12c Talk with healthcare provider

$52 / 105$ (50\%; 37 to 62$)$

P12d Go for a walk

$5 / 105(5 \% ; 1$ to 10$)$

P12e Massage

$1 / 105(1 \% ; 1$ to 3$)$

P12f Talk with friend or relative 
Table 1 continued

\begin{tabular}{ll}
\hline Perioperative management details & \\
\hline P12g Distraction with toys or electronic device & $9 / 105$ (9\%; 2 to 16$)$ \\
P12h Positive thinking & not age-appropriate-not enquired \\
P12i Relaxation & $3 / 105(3 \% ; 0$ to 7$)$ \\
P12j Sleep & $14 / 105(3 \% ; 5$ to 27$)$ \\
P12k Other & $15 / 105(14 \% ; 5$ to 23$)$
\end{tabular}

Denominators reflect available data

*There was no use of heat or deep breathing

$\mathrm{CI}=$ confidence interval; $\mathrm{GA}=$ general anesthesia; $\mathrm{IPOQ}=$ International Pain Outcomes Questionnaire; IQR = interquartile range; LA = local anesthetic; NSAID = non-steroidal anti-inflammatory drug; RA = regional anesthesia; $\mathrm{SA}=$ spinal anesthesia

patients received only paracetamol, 11 only NSAIDs, and one only an opioid. Other results are found in the Table 1.

As we found in our previous adult study, the worst postoperative pain was high in over half the patients, but the median [IQR] score for satisfaction was also high (8 [7-9]). Postoperative pain was apparently expected by participants and accepted as unavoidable. We postulate that patients and parents were more concerned about getting the surgery done than about pain. This is borne out by a study of 1,626 households with a $99 \%$ response rate that found that $6.3 \%$ of Rwandan children have a potentially treatable surgical condition. ${ }^{6}$ Healthcare is improving rapidly in Rwanda. We expect that the present study will suggest areas for improvement of traditional postoperative pain measures, and that the IPOQ results may inform some new directions for quality improvement. We plan to repeat the study to measure any improvement after four or five years depending on the COVID-19 pandemic status.

Acknowledgements The authors would like to extend their thanks to data collectors Rose Nyinawingeri, Bob Sumayire, and Jean de Dieu Mahoro.

\section{Disclosures None.}

Funding statement We are grateful to the Departments of Anesthesiology of the Universities of Rwanda and Saskatchewan for funding this study, and to the Canadian Anesthesiologists' Society International Education Foundation for providing housing in Kigali for the Canadians.
Editorial responsibility This submission was handled by Dr. Stephan K.W. Schwarz, Editor-in-Chief, Canadian Journal of Anesthesia/Journal canadien d'anesthésie.

\section{References}

1. McKay WP, Lee D, Masu A, et al. Surveys of post-operative pain management in a teaching hospital in Rwanda - 2013 and 2017. Can J Pain 2019; 3: 190-9.

2. Hodges SC, Mijumbi C, Okello M, McCormick BA, Walker IA, Wilson IH. Anaesthesia services in developing countries: defining the problems. Anaesthesia 2007; 62: 4-11.

3. Ferreira-Valente MA, Pais-Ribeiro JL, Jensen MP. Validity of four pain intensity rating scales. Pain 2011; 152: 2399-404.

4. Rothaug J, Zaslansky $R$, Schwenkglenks $M$, et al. Patients' perception of postoperative pain management: validation of the International Pain Outcomes (IPO) questionnaire. J Pain 2013; 14: 1361-70.

5. Eshete MT, Baeumler PI, Siebeck M, et al. Quality of postoperative pain management in Ethiopia: a prospective longitudinal study. PLoS One 2019; DOI: https://doi.org/10. 1371/journal.pone.0215563

6. Petroze RT, Calland JF, Niyonkuru F, et al. Estimating pediatric surgical need in developing countries: a household survey in Rwanda. J Pediatr Surg 2014; 49: 1092-8.

Publisher's Note Springer Nature remains neutral with regard to jurisdictional claims in published maps and institutional affiliations. 